\title{
Keeping the business going: SMEs and urban floods in Asian megacities
}

\begin{abstract}
Flooding presents one of the main risks to contemporary and future cities, especially those in coastal zones. Given the social-political nature and construction of urban flood risks, it is of crucial importance to understand how such risks are experienced and addressed, and by whom. This article aims to contribute to this by focusing on a particular actor, i.e. entrepreneurs of small and medium enterprises (SMEs). It asks how SMEs experience, perceive and address risks. This knowledge not only can help to improve flood governance by including one group's specific risks and opportunities but also provides new insights into how risk perceptions are constructed and shape subsequent strategies. The findings are based on a comparative study of SMEs in Jakarta, Metro Manila and Bangkok. Using a mixed methods design, the studies show that entrepreneurs distinguish between frequent everyday floods and scarce major floods, but only consider major floods a risk. The latter is explained by a combination of risk normalisation and incremental and independent everyday practices. Strategies aim at keeping the business going in the short run. There are substantial differences between medium and small companies. Finally, the research confirms that attention for SMEs in flood policies or support is nil.
\end{abstract}

Keywords: flood, cities, risk, SMEs, Jakarta, Bangkok, Metro Manila, adaptation, vulnerability

\section{Introduction}

Flooding and other extreme weather events are some of the main risks threatening contemporary and future societies (Wong et al., 20I4). As shown by recent dramatic events such as in Beira (2019, Mozambique) (Devi, 2019), Freetown (2017, Sierra Leone) (Redshaw et al., 20I9), and Houston (20I7, USA) (Sebastian et al., 20I7), cities, and those in coastal zones especially, are particularly vulnerable to flooding. Urban flooding is the result of different and often combined natural, i.e. meteorological and hydrological, and human-induced causes. While climate change is often not a (sole) cause of urban flooding, it is expected to further increase the incidence and severity of flooding (Jha et al., 2012).

Flooding impacts those living, working or operating businesses in the city (Dodman et al., 2013). Besides human loss, it affects the built environment and economic infrastructure, water availability and resources, and cultural heritage (Pathak and Ahmad,

Hebe Verrest is Assistant Professor at the Amsterdam Institute for Social Science Research, Laerke Groennebaek is graduate of the Master Program International Development Studies of the Graduate School of Social Sciences, Adele Ghiselli is graduate of the Master Program International Development Studies of the Graduate School of Social Sciences, and Mariana Berganton is graduate of the Master Program International Development Studies of the Graduate School of Social Sciences at University of Amsterdam, Nieuwe Achtergracht I66, Amsterdam ior8 VZ, Netherlands; e-mail: h.j.l.m.verrest@uva.nl; llykkeg@gmail.com; adele.ghiselli@gmail.com; mariberganton@gmail.com 
2016). However, flood risks and their impacts are not distributed evenly between or within cities, but bear a clear social-spatial pattern. Firstly, cities in low- and middleincome countries and poor residents within cities are more affected by urban climate risks such as flooding (Berquist et al., 2015; Dodman et al., 2013). Secondly, cities in low-elevation coastal zones and people living and working in informal urban settlements near waterways are more vulnerable (McGranahan et al., 2007). Moreover, in line with Ulrich Beck's (1992) notion of the 'risk society', the impact of risks on people, areas and businesses depends on their subjective understanding of these, on location, preparedness and socio-economic factors and is therefore a social-political, hence governance, question (Beck, I992). Consequently, as is the core of (urban) political ecology (e.g. Swyngedouw, 2004), flooding and risks are (re)produced through social, political and economic structures and processes. Given this social-political nature of urban floods and the risks they pose, it is crucial to understand how such risks are experienced and addressed, and by whom. This article aims to contribute to this understanding by focusing on a particular actor, i.e. entrepreneurs of small and medium enterprises (SMEs).

Both in the global North and global South, the private sector is considered an important actor in flood governance and broader climate action (Plummer et al., 20I8). This importance can partly be traced to the rise of neoliberal governance, moving away from the state as the main governance actor to include multiple parties, prominently the private sector. Moreover, its ability to invest, innovate and provide (technical) expertise is considered pivotal. Enterprises may develop individual adaptation strategies, or contribute to collective attempts to make urban infrastructure and economies more flexible, responsive and resilient (e.g. Evans, 1997). Finally, enterprises are crucial in developing innovative mitigation strategies. However, while current flood and broader climate governance literature consider the private sector important, in practice this sector is largely treated as a 'black box', obscuring much of the dynamics and diversity within the sector. Firstly, there is little attention for variations within the sector such as firm size or enterprise type (Neise and Diez, 20r9; Biagini and Miller, 20I3). Secondly, considerations of how entrepreneurs perceive and experience flood risks, are largely absent. Thirdly, discussion of the actions taken by entrepreneurs and how these are shaped by understandings of (flood) risk and governance practices, has only started to emerge and is mostly based on individual case studies (Neise and Diez, 20I9; Marks and Thomalla, 20ı7; Chinh et al., 20ı6). Finally, the implicit focus in many academic and policy discussions is on large and multinational companies with SMEs only recently becoming a focus of attention (Marks and Thomalla, 20I7; Chinh et al., 2016; Wedawatta et al., 2014; Agrawala et al., 2013). Nonetheless, given that SMEs account for a significant share of all private sector businesses, they are a particularly relevant group to consider. Moreover, SMEs play a crucial role in urban economies, contributing to urban labour opportunities, while providing products and 
services (Ingirige and Wedawatta, 2018; Schaer and Kuruppu, 2018; Wedawatta et al., 20I4). Therefore, SMEs' understanding of and vulnerability to risks as well as their strategies - or lack thereof - to address these risks may impact urban life considerably.

In order to address the challenges posed by urban environmental risks, we need to better understand how SMEs experience, perceive and address such risks, and how these are related to business characteristics, and local complexities (Wedawatta et al., 20I4; Bulkeley and Betsill, 2013). Such knowledge is not only important to better incorporate the needs of SMEs in flood governance and climate action, but given the intrinsic relation between risk and entrepreneurship and the diverse ways in which SMEs deal with risks may provide new insights into the social-political nature of the construction of risk perceptions and actions. This article examines the aforementioned questions, thereby focusing on urban floods. Data was collected during ten weeks of fieldwork in flood prone communities in three Asian cities vulnerable to flood risks: Bangkok, Jakarta and Metro Manila. It was conducted by three MSc students (all authors of this paper) of International Development Studies (University of Amsterdam) in early 2017 as part of their thesis projects. After a literature review, discussion of the main theoretical debates underpinning this article, and methodological accountability, the article addresses the questions of this research.

\section{Theoretical background}

\section{Understanding (flood) risks}

Urban floods emerge as a combination of natural and human-induced causes. Jha et al. (2012) categorise urban floods as fluvial, coastal, flash, pluvial and groundwater floods. These are driven on the one hand by (combinations of) hydrological and meteorological extremes and on the other human activities, including land-use changes (reduced permeability, land subsidence, disappeared floodplains) and (qualitatively and quantitatively) inadequate drainage and sewage systems. Based on an analysis of existing disaster databases, they conclude that since $195^{\circ}$ the yearly incidence of flood related disasters is increasing, especially in urban areas. In addition, the largest share (43 per cent, or over 3,00o) of reported disasters between 1998 and 2017 were floods (Wallemacq and House, 2018). While fatalities of flooding are reducing, financial damage is increasing. Calculations of incidence and flood impacts are mostly carried out in relation to major floods or disasters, excluding the impacts of frequent, 'semi-permanent' and often minor floods which are long-term, subtle and hard to quantify (Jha et al., 2012). Floods may well be part of everyday lives, rather than an exceptional event (Arabindoo, 2016). Given the unequal social and spatial distribution of flood risks, with low-income areas and low-lying areas much more vulnerable, it is to be expected that such semi-permanent floods are more frequent in these areas. 
Understandings of the concept of risk are basically driven by two distinct theoretical approaches. The first understands risks as objective and external (Dessai et al., 2004 as discussed in Douglas, I992) that can be tackled with technical solutions. It focuses on probability measurements of an event happening and identifies a certain threshold as a critical point beyond which impacts will be felt. Examples are the i:Iooyear flood risk, or (generally related to climate change) the Small Island Development States discussion around $\mathrm{I} .5^{\circ}$ to stay alive (Sealey-Huggins, 2017). The other, particularly developed from Ulrich Beck's 'risk society' (I992), states that risks are relational, that they are social constructions and by essence subjective and political. As such, risks are not only based on the probability of an event but also how it is perceived and appreciated by individuals (Dessai et al., 2004). This in return is shaped by a combination of individual characteristics, including knowledge, alongside local political, social and economic contexts and discourses. As such, risk is considered in relation to politics, power, policy and vulnerability, emphasising that risk is shaped by resilience and adaptive capacity, as well as by inequality (Fraser et al., 20I6). When focusing on flood risks, we can do so based on past events and the likelihood of them happening again (given particular uncertainties), or by constructing risks from climate modelling. In this study we build on Ulrich Beck's work and understand risks as social constructions, in particular drawing from the understanding that risks are subjective and shaped by knowledge based on past experiences and/or through knowledge about climate models, individual characteristics and adaptive capacity.

\section{Risks and entrepreneurs}

Conventional understandings of entrepreneurship generally focus on either selfemployment or highlight the potential for economic innovation. Entrepreneurs therefore are thought to be innovative, creative and, in particular, risk-taking (Carland et al., I988). Firstly, 'taking risks' is considered a central, positive characteristic of entrepreneurial behaviour, regardless of business or the context in which entrepreneurs work (Naldi et al., 2007). Entrepreneurs innovate and take risks by investing money and time in products and services that may or may not return investments. Furthermore, being self-employed and business owners, they operate in an environment where market, financial and economic conditions are highly conducive to the success or failure of businesses. For a long time, therefore, being an entrepreneur was almost equal to risk-taking. Much literature, deploying a more objective approach to risk, discusses methods to make proper risk assessments, focusing on probabilities (e.g. Falkner \& Hiebl, 20I5). However, recently, we increasingly see work that questions the notion that entrepreneurs are by definition risk takers (North, 2016; Verrest, 2013). Such work, particularly in the global South, shows that characteristics of entrepreneurs, including risk behaviour, are diverse and shaped by the agency of entrepre- 
neurs, personal characteristics and by social and economic contexts. As such, risks are increasingly understood as subjective and relational. This is particularly true for small and micro entrepreneurs (as opposed to medium and large businesses), for entrepreneurs in the global South and for vulnerable entrepreneurs with limited resources and infrastructure to insulate from risks (Grimm et al., 2012). Such entrepreneurs may avoid risks, preferring lower but stable income to insecure and volatile growth, create small and incremental investments from personal savings or business profits, focus on mainstream activities, and combine multiple (small) economic activities (Verrest, 2013; Grimm et al., 2012). For that reason, different types of entrepreneurs may perceive and appreciate different risks differently. Subsequently, they may use different approaches to address these (North, 20i6).

Given the rise in incidence and severity of floods, they are a concern for SMEs. Floods may cause direct economic losses due to damaged productive assets (e.g. machinery, buildings), affected human assets (e.g. staff availability), or halted production processes (e.g. infrastructure and transportation problems) (Wedawatta and Ingirige, 2012). Furthermore, indirect effects, including general economic downturn, or anxiety (Marks and Thomalla, 2017) are often overlooked in flood damage analyses (Chinh et al., 20i6), but may also impact businesses. Generally, estimates of flood damage consider insured assets rather than uninsured or informal assets (Patankar and Patwardhan, 20I6). The particular vulnerability of SMEs relates to their size and sometimes location that makes them more prone to risk with lesser coping mechanisms at hand (Josephson et al., 20I7). However, medium sized enterprises are somewhat better off regarding the coping mechanisms accessible (Neise and Diez, 20i9; Grimm et al., 2012).

\section{Vulnerability}

Vulnerability-thinking considers how businesses, individuals or states anticipate risks, the impact of risks and the ability to cope with them. Vulnerability is understood here as 'the characteristics of a person or group and their situation that influence their capacity to anticipate, cope with, resist and recover from the impact of a natural hazard' (Blaikie et al. 2004). Building on definitions of vulnerability from Moser et al. (20I0 ) and Füssel (2007), we understand vulnerability as a function of sensitivity and of adaptive capacity. Sensitivity includes exposure in combination with experiences and impact. Exposure is the degree of stress upon a system and may be represented by either long-term changes in the natural and human-induced flood conditions, or by changes in climate variability (IPCG, 20I4; Jha et al., 2012). Impact refers to 'the degree to which a system is instantly affected by a perturbation' (Füssel, 2007). Adaptive capacity is the inherent ability of a system to evolve or undertake actions in order to avoid loss and/or recover rapidly from hazards (Moser et al., 20Io). It 
includes the capacity to prepare, resist or cope with a risk adapt by accessing knowledge, skills, goods and services. In this regard, vulnerability is a combination of sensitivity and capacity to cope or adapt. Vulnerability is a social-political question starting from the position that both sensitivity and adaptive capacity are shaped through social differentiation, and power inequality. Consequently, the extent to which businesses are sensitive to flood risks as well as the extent to which they are able to cope with such risks is related to a number of factors: their location and infrastructural dimensions of their location; the type of business being carried out and its dependence on a fixed location; perceptions of the risk itself; accessibility to and perceptions of the effective actions, and; access to the skills, services and assets to realise such actions (Bubeck et al., 2012).

A number of recent SME studies discuss flood adaptation. Neise and Diez (2019) focus on manufacturing SMEs in Jakarta and Semarang. The study concludes that while larger businesses adapt more effectively than smaller businesses with fewer resources and less adequate strategies, both are experiencing business viability issues as a result of increased flood risks. They argue for a better understanding of adaptation strategies among different entrepreneurs. Pathak and Ahmad (20i6), examining strategies from SMEs in Thailand, conclude that SME owners underestimate flood risk, and that their coping strategies lack addressing long-term and recurring floods. Consequently, they are not improving flood preparedness. The strategies however, do make adequate use of local government assistance and strategies. In a study on the Mekong Delta (Chinh et al., 20I6), it was found that SMEs consider adjustments to their building (such as flood barriers or elevation) the most effective measures.

As Marks and Thomalla (20I7) show, the extent to which SMEs can recover from flood is not only dependent on social or economic factors but also on actions from the state in collaboration with other partners. This concerns flood recovery and support measures but also broader social or economic policies. The many studies on flood adaptation, preparedness and associated governance models, highly value vertical (global, state, city and local level) and horizontal (private, state and civil actors) integration (Plummer et al., 2018). In this respect, actions at the individual level of households, businesses and individuals are usually only effective when connected to neighbourhood or city-wide actions. As studies by, for example, Pathak and Ahmad (2016), Patankar and Patwardhan (2016) and Parthasarathy (2015) show, SMEs are often not properly included in flood governance measures. For example, specific support (short-term or long-term) measures may be lacking, or non-quantifiable and informal damage is excluded from assessments. Similarly, some measures may actually increase SMEs' vulnerability to floods (Marks and Thomalla, 2017), or relevant community-level interventions may prevail over individual property-level based measures, leaving SMEs on their own if they want to increase flood resilience of their property (Wedawatta and Ingirige, 2012). 
To conclude, in order to understand SMEs' vulnerability to flood risks, this study brings together knowledge and debates in the field of risk, entrepreneurship and adaptation. This review then leads to the following questions: how do SMEs experience and perceive flood risks and flood impacts, and what strategies do they deploy to address these?

\section{Context and methodology}

This study employs a comparative case approach, including flood prone communities in three coastal Asian capital cities; Jakarta, Metro Manila and Bangkok. The cities share characteristics including their coastal location and exposure to flood risks, but political and economic trajectories have produced potentially distinct contexts in which SMEs operate and floods take place. As such, this comparison allows us to broaden our understanding of SMEs and flood risks across different cases and to distinguish between what is context-specific and what is potentially universal across and beyond the cases. To be able to address the impact of flood risk on SMEs we have chosen communities that bear a significant flood risk and contain a substantial SME population. As such, the studies areas are not representative for the cities, but are relevant cases for the research aim. References to the cities in the analysis should therefore read as flood prone communities in these cities.

Situated in a low basin, thirteen major rivers and countless canals run through Jakarta. These many waterways, combined with heavy rainfall, insufficient drainage and rising sea levels, make Jakarta one of the cities with the highest flood hazard in the world, and set to increase in the future (Garschagen et al., 2018). In addition, the city experiences heavy land subsidence, mainly due to groundwater extraction and construction developments (Abidin et al., 2015). The typical yearly subsidence rate is 4-Io cm, but the northern coastal area experiences up to $28 \mathrm{~cm}$ (Abidin et al., 20I5). Subsequently, nearly half of Jakarta, especially the northern coast, is below sea level. While reduction of land subsidence would be the most effective countermeasure to mitigate coastal floods (Takagi et al., 2017), ill-maintained and clogged waterways alongside land-use change also have substantive negative impacts on water management in the rapidly growing megacity (Pribadi et al., 2018). In 20I7, there were several incidents of flooding of up to I.5 $\mathrm{m}$ deep. The last major flooding, in 2013, put 70 per cent of the city under water up to $4 \mathrm{~m}$ and caused tremendous human and economic losses. Research was conducted in three districts on the northern coast of Jakarta, dominated by the fishery industry: Muara Angke, Muara Baru and Cilicing.

Metro Manila's geography and urbanisation render it highly susceptible to floods. The fast-growing megapolis is situated in a low-lying river basin, crossed by three rivers and multiple canals. Its exposure to frequent extreme weather events, such as typhoons, strong rains, earthquakes, volcanic eruptions, droughts and floods turns it into 'a vast 
drainage basin that experiences frequent inundations from overflowing rivers and storm waters' (Liongson, 2000 cited in Bankoff, 2003). Climatic conditions, paired with poorly coordinated land-use regulations, infrastructural development and building practices, have produced increased land subsidence (Porio, 20I4). Furthermore, the disappearance of numerous canals due to the filling of waterways for real estate and commercial activities, as well as construction on wetlands, have increased flood risks. The reduction in waterways is further enhanced by a lack of sufficient sewerage, drainage and waste disposal sites (Bankoff, 2003). Typhoons and flash rains have grown in frequency and intensity throughout the twentieth century. In 2009, the devastating typhoon Ondoy caused floods up to several metres high in over 7o per cent of the city. Likewise, sea-level rise poses increasing threats to coastline communities, while flood related economic losses have increased eighteen times over the past century (Porio, 20I4). This study focused on the municipality of Pasig City which is traversed by two rivers and the Manggahan floodway. The research focused on the Southern Kalawaan and Pinagbuhatan, and Northern Santa Lucia and Maybunga barangays.

Occupying a vast area of the Chao Phraya River delta, Bangkok has a low-lying topography and is at constant risk of river (fluvial) and overland (pluvial) floods (Saito, 20I4). In the relatively flat basin, floodwaters drain away slowly and flood-durations are long (Gale and Saunders, 20I3). This issue is further exacerbated by the filling of canals and land subsidence from deep-well pumping which has severely affected the city (Marks, 2015; Phien-wej et al., 2006). Since i993, urban Bangkok nearly doubled in size at the expense of rural and agricultural areas (Posuk et al., 2018). This rapid land-use change has caused grave environmental problems, while weak governance has been a strong reason for the severe impacts of the 20 I f flood and for very little policy learning following past floods (Lebel and Lebel, 20ı8; Marks and Thomalla, 20I7). In addition to yearly monsoon floods, abrupt flash floods have become a significant problem. In 20 I , Bangkok experienced the worst flooding in history, which lasted I58 days (Marks, 2015; Saito, 20I4). The focus of our study is on the Don Mueang district, which was, within the metropolitan area, among the most flooded in 20 I I and is one of the first affected during the monsoon season.

The study employed an identical mixed methods research design using qualitative and quantitative methods in each location. Such design presented an opportunity to reach a relatively large number of respondents, triangulate data and discover patterns in a fairly short - i.e. ten weeks per city - fieldwork period. The fieldwork was conducted between late January and early April 2017. This period overlapped (partly) with monsoon in Jakarta but was dry in Metro Manilla and Bangkok. A face-to-face quantitative survey, was undertaken with (approximately) 6o SMEs per city. The SMEs were classified as being small or medium sized, based on self-reporting of the number of employees. While, additionally, all countries use turnover or asset-based criteria to classify SMEs, we did not use this criterion, the reason being that entrepreneurs 
were not able or willing to disclose income data. A lack of a reliable (and identical) sample frame made random sampling in all cases impossible. Using a combination of purposive and snowball sampling, we aimed to develop a comparable composition of respondents in each city. In addition to the diversity in economic sectors and size in each city, we included entrepreneurial characteristics such as gender, age and educational background (Table I). The survey consisted of closed questions and addressed flood experiences, impacts, risk perceptions and actions, including sources of information and perceptions regarding roles and responsibilities of different actors. Questions included for example whether entrepreneurs need financial support for risk prevention, how they perceive flood risks and when they last experienced negative business impact of a flood. The structure was identical across cities but was adapted to local specificities (e.g. a specific typhoon or a specific government intervention). While quantitative data provided general knowledge and data, we collected qualitative information to get a better understanding and contextualisation of these data. Firstly, eight to fifteen semi-structured interviews with SMEs were held in each city to elaborate findings from the survey, triangulate data and discuss business functioning. The interview guide was partly developed from notes taken from additional information provided during the survey. Where we present percentages, these come from the survey; elaborations are derived from corresponding survey questions which have been triangulated in the qualitative interviews, or directly from the qualitative interviews. Secondly, semi-structured interviews were conducted with approximately ten experts per city, from national, regional and local government agencies, academia and NGOs. These experts offered insights into the urban environmental governance structure, climate and flood policies and action, and how these affect SMEs.

Table 1 Characteristics of surveyed entrepreneurs

\begin{tabular}{|c|c|c|c|c|c|}
\hline & Size & $\begin{array}{l}\text { Number of } \\
\text { employees }\end{array}$ & Sample & $\begin{array}{l}\text { Gender } \\
\text { (M/F) }\end{array}$ & $\begin{array}{l}\text { Average age } \\
\text { of owner* }\end{array}$ \\
\hline & & & 60 & $87 \% / 13 \%$ & 43 \\
\hline \multirow[t]{3}{*}{ Jakarta } & Small enterprise & $10-49$ & 50 (81\%) & $84 \% / 16 \%$ & 40 \\
\hline & Medium enterprise & 50-149 & $10(19 \%)$ & $100 \% / 0 \%$ & 46 \\
\hline & & & 60 & $48 \% / 52 \%$ & 47 \\
\hline \multirow[t]{3}{*}{ Manila } & Small enterprise & $10-49$ & 45 (75\%) & $44 \% / 56 \%$ & 47 \\
\hline & Medium enterprise & 50-199 & $15(25 \%)$ & $73 \% / 27 \%$ & 47 \\
\hline & & & 62 & $37 \% / 63 \%$ & - \\
\hline \multirow[t]{2}{*}{ Bangkok } & Small enterprise & $10-49$ & 48 (77\%) & $40 \% / 60 \%$ & - \\
\hline & Medium enterprise & $50-249$ & $14(23 \%)$ & $29 \% / 71 \%$ & _- \\
\hline
\end{tabular}

* This was not asked in Bangkok, because of expected sensitivity 


\section{Findings}

Flood sensitivity: experiences, impacts and perceptions

\section{Experiences}

Studied SMEs in North Jakarta considered flooding, mainly resulting from high tide and heavy rain, the most common climate-related risk. All surveyed SMEs in the area have experienced flooding, in particular tidal flooding, which may occur twice a month and can reach all the way inside homes and business premises. The vast majority (8o per cent) of these SMEs experienced flooding within one year prior to the study. Recently however, the SMEs in Cilincing have seen a decrease in flooding frequency, most likely due to infrastructural improvements including elevation. Moreover, flood duration decreased in all three districts from several days or even weeks per event to around one day. The qualitative interviews showed this to be considered a result of projects to clean waterways in the city, initiated by former governor 'Ahok'.

In Manila's researched communities, nearly all (98 per cent) surveyed SMEs have experienced flooding in or around their business at least once during their lifetime, with water levels up to $4 \mathrm{~m}$ and durations of more than three months. The highest water level was reported in Santa Lucia, and the longest duration in Maybunga, both being particularly low-lying and situated along the Pasig River. Typhoons (9o per cent) rather than monsoon rains (Io per cent) were considered the main flood cause. Interestingly, none of the surveyed SMEs experienced flooding in the year prior to the research and in all barangays SMEs report reduction in flood occurrence. For 62 per cent, the last significant flood experience dated back to monsoon Habagat (2012-2013), and for $3^{8}$ per cent to typhoon Ondoy (2009). Currently, while Metro Manila floods once a year on average, this statistic is lower in Pasig City.

In Bangkok's Don Mueang, 95 per cent of businesses surveyed have experienced flood at least once in the past decade, and go per cent experienced flood in $201 \mathrm{I}$ when the worst flood in history hit the city. The duration of this flood varied widely for the SMEs but was $5^{8}$ days on average (minimum io days and maximum 120 days). In addition to big floods such as in 201 I, 57 per cent of the SMEs experience 'mild' floods every year during the monsoon and report that these seem to get worse in duration and intensity. The duration of these 'mild' or everyday floods vary from an hour to a full day with frequencies ranging from twice a week to twice a month.

\section{Impact}

In the four years previous to this research, 93 per cent of interviewed SMEs in Jakarta were negatively affected by flooding. The most frequently mentioned impact, also causing most distress was economic loss, including the inability of staff to work, of 
selling products and damage to buildings. The severity of damage depends very much on business size, with larger businesses having a more solid base for coping while small businesses and fisherman cooperatives (KUBs) were particularly sensitive. Next to economic impact, SMEs, in particular the smaller ones, experienced social implications, including stress and anxiety from the uncertainty of their business operation. Another crucial impact, caused partly by drastic land subsidence in north Jakarta, was forced relocation (28 per cent of SMEs), which in turn contributed to disruption of livelihoods and had strong negative economic and social implications for business owners.

In Manila, $9^{8}$ per cent of interviewed SMEs have been negatively impacted by floods. Inability to secure business operations caused the highest concern with the biggest impacts being interruption of activities (84 per cent), inability of employees to come to work (63 per cent), water and electricity cuts (55 per cent), and damage to raw materials (55 per cent). Social impacts included psychological issues, such as anxiety and sadness (53 per cent), physical injuries or diseases (32 per cent) and relocation (I6 per cent). The severity of impacts varied, depending on available financial assets, technical know-how, business specificities (e.g. operating with perishable materials), and social aspects (e.g. having to take care of a family).

The 20I I floods in Bangkok damaged 9i per cent of the buildings and offices of studied SMEs and 86 per cent explained that their employees were unable to reach work. This culminated in a loss of business opportunity which was reported as the biggest impact. While experiences of damage in 20I in Don Mueang were common across sectors and size, SMEs in manufacturing experienced damage more often (8o per cent) than those in the commercial (63 per cent) or service (4I per cent) sector. Regarding the yearly 'mild floods', most SMEs did not acknowledge much damage. The businesses described having to work their way around the flood situation, changing their working habits and space, but did not report that this type of flooding created significant economic damage as business continued.

We were not able to collect reliable data on financial impact but the experiences across cities showed that the impact that floods (and in particular the large flood events) have on business continuation and social stress are most significant.

\section{Perceptions}

Most of the interviewed SME-operators in Jakarta perceived flood risks as uncontrollable. When asked to indicate their primary concern for their operation, 48 per cent of SMEs mentioned flooding and only i2 per cent financial concerns. For the remaining 40 per cent, a large land reclamation project in Jakarta Bay was the primary source of concern as it is predicted to severely implicate the fishery sector. Respondents built their knowledge on personal experiences. Technical or scientific 
knowledge regarding causes of and possible solutions to flood related issues was practically non-existent.

In Pasig City, 77 per cent of the studied SMEs considered flood a serious concern. However, recent infrastructural improvements (dyke walls, improved drainage system, water pumping stations) have been successful, at least for the time being, and one-third of SMEs considered flooding 'under control'. Furthermore, most SMEs perceived flooding one among many risks, including earthquakes and fires, income insecurity and crime. Floods were related by respondents to climate change but their knowledge is built on everyday experienced changes in weather, and not on scientific data or forecasts.

Interviewed SMEs in the Don Mueang district perceived flood as a risk only when it disrupts their business operation and damages their production, buildings and supplies. Along those lines, while businesses acknowledged that 'mild floods' happen on a regular basis and get worse, they did not consider these floods as risks. Events such as the 20 i f flood were considered a risk implicating their business which required action from third party actors, mainly the government. Regarding the future prospect of flood risk, 73 per cent of these SMEs saw little chance of flood occurring as badly as in 20I , and also that potential damage would be less than in 20I . Across the board, floods such as those of 20 I I were mostly associated with a lack of water management.

In all three cities, the impact of floods on business continuation concerned SMEs the most. Although nearly all SMEs have been negatively impacted by flood in recent years, they clearly distinguished between major floods - fairly rare but considered a significant risk - and the frequent 'everyday' floods, which were not considered a notable risk, mostly because SMEs have found ways to continue business operations during these floods (see below). Perceptions of flood risk were based on lived experience and much less on scientific modelling and assessment.

\section{Adaptive strategies}

In Jakarta, adaptive actions were widespread. Of the studied SMEs, almost all (93 per cent) acted during or after flooding. The most common action - regardless of business size - was elevation of the building in order to stop water from entering buildings and damaging means of production or halting business operations. Surprisingly, a staggering 85 per cent of SMEs who did this still experienced flooding, albeit at a lower level and generally not causing large business disruptions. As such, these interventions met the aim of SMEs to keep the business going. Of the SMEs that undertook action, 93 per cent used their own financial capital and i3 per cent (also) used a loan as there was no state support. Insurance was rare; 7 per cent of studied SMEs had some form of insurance but only one was partly covered in relation to disaster losses. The study found less vulnerable entrepreneurs were more inclined to 
act with regard to structural types of action such as voluntary relocation, finding flood prevention information and waste management.

Also in Manila, adaptation strategies, both in reducing sensitivity to current risks and in enhancing adaptive capacity to future risks, were widespread. During flooding, government relief operations together with help from social networks supported the surveyed enterprises. Also here, business owners resisted closing down business activity, often at any cost. Almost all (92 per cent) SMEs have undertaken action after a flood, among which the most common were securing employees with shelter and medicines (85 per cent) and community donation (79 per cent). Long-term and more structural actions such as business continuity plans ( $5 \mathrm{I}$ per cent), training (29 per cent), and adaptation of the building (37 per cent), differed substantially between small and medium-sized businesses. Medium-sized enterprises, mostly wealthier, could undertake more such transformative actions. The majority of small businesses however, engaged in informal training in the form of mutual exchanges, and incremental business-building restructuring. Formal loans and insurances were taken out by I3 per cent of studied SMEs and two small enterprises have used informal loans. Consequently, SMEs' actions largely relied on social networks for immediate material help. Finally, actions were undertaken in response to City Hall requirements with regard to pollution standards, waste management and plastic reduction. Adaptation practices were first and foremost aimed at preventing business disruption and secondly strengthening community ties.

The 20I I flood in Bangkok was an important marker for SME adaptation strategies. While few of the studied businesses had undertaken action to prevent major floods before 20II, this changed after. Almost 57 per cent of the SMEs mentioned having modified their buildings after 20I. In addition, businesses invested in developing their flood knowledge (50 per cent), product diversification (47 per cent) and environmental plans (44 per cent). Business size influenced the actions taken: while $5^{8}$ per cent of all studied businesses undertook some action, 92 per cent of medium businesses have used a substantial number of these strategies, while only 49 per cent of small business have. A third had some form of risk insurance but were mainly medium-sized businesses. For overcoming 'mild floods' on a daily basis, SMEs relied primarily on survival and everyday practices, such as relocation to a higher floor, or working while standing in water. Regarding 'mild floods' and future events, the majority of businesses said that they continued to use the same tools as in 20II and only medium-sized businesses were willing to invest in adjustments or other tools.

Long-term strategies by SMEs were aimed at business continuity, including elevation of buildings. Although many of these adaptive strategies have not eliminated flooding, they have prevented large business disruptions and allowed the SMEs to continue their work, which made SMEs consider them good adaptation practices. Adaptive capacity differed a lot from business to business and depended both on size, location and type with the larger and less vulnerable businesses better positioned. 


\section{Governance interventions and vulnerability}

In debates on risk and vulnerability from a political ecology perspective, the role of the state at multiple levels, and its interactions with other actors is considered crucial. Hence, for the final section of our discussion we turn to experiences of SMEs with the state at local and city level. Specifically, we address to what extent and how SMEs are included in flood-related policies, which flood interventions SMEs experience and in what way, and finally the kind of support SMEs receive from the state.

In Jakarta, the city government - under the leadership of then governor 'Ahok' -implemented measures to increase flood resilience including cleaning of canals and elevation of streets (van Voorst, 20I6). While the northern districts were largely overlooked as they are economically less promising, one of the research communities was included. Respondents here reported lower flood incidence and higher appreciation of government efforts than in the other research communities. Nevertheless, flood is still a critical risk and in response, a giant sea-wall project has been initiated. This project however mainly responds to large business concerns and will have negative implications for SMEs in the fishery sector (Gass et al., 20I I), including those in Northern Jakarta. As such, this wall is considered the largest risk by the studied entrepreneurs. SMEs had not been included in any flood-related laws or policies at either national, city or local level, except for one: relocation. Relocation was promoted by the city government in its National Capital Integrated Coastal Development master plan, as a sustainable and prosperous solution for those living and working in bad conditions near major waterways. Although relocation is financially supported by the government, the involved SMEs perceived this to be detrimental for their livelihood, as they are relocated far away from the shore in high-rise accommodation unsuitable for business. Apart from relocation, elevating the business, as a majority of the studied SMEs have done as an adaptive measure to minimise flood impact, was only in three cases supported financially by the government. None of the interviewed SMEs reported that they have been compensated for losses after flood events. While some communities in Jakarta have protested against insufficient flood response (Padawangi and Douglass, 2015), there was no record of SMEs in the studied areas campaigning for better flood protection, despite the fact that only around a quarter believe that the government already does enough to prevent flooding.

After typhoon Ondoy in 2009, and in order to reduce disaster risks, the Philippines developed mitigation and adaptation strategies at all levels of governance. In Pasig City, the local government implemented sustainability guidelines to develop a flood-proof city. Measures included building dyke walls, improving drainage and installing water pumping stations. In addition, the local government focused on public awareness of environmental protection. According to multiple SME and expert interviewees, these strategies gained massive public attention and shaped local flood risk perceptions, and also entrepreneurs feel much safer in relation to flood risks than a few 
years ago (see the previous section). Nonetheless, while these measures may have been successful at Pasig City level, at Metro level they have relocated the problem rather than solving it (Gera, 2018). In this respect, many of these measurements are considered unsustainable in the long run as they cannot withstand growing climate change impacts and go hand-in-hand with the continuation of unsustainable practices such as building on perilous locations (Porio, 20I4). According to interviewees, Pasig City was included well in local political debates and has enough capacity to meet its responsibilities. However, its efforts to realise a change of culture are jeopardised by general distrust in the government's goodwill (Porio, 20I4). In this study, no SMEs mentioned having received any financial support from government, rather, they have recovered using their own financial capital. Moreover, business concerns are not sufficiently considered in policy development and disaster risk management, as local authorities lack funding to cover all population groups in the specific area capacity to support businesses' needs (Porio, 20I4). SMEs, including the larger ones, argued that in order to overcome medium or long-term risks, they required more information and economic means. Yet, there was no record of SMEs campaigning for better flood protection.

Many governance actors in Bangkok and Thailand work on different projects and plans to foster flood action, creating a fragmented governance approach, reducing its effectivity (Lebel and Lebel, 20I8; Marks, 20I5). However, raising floodwalls around Bangkok, including in Don Mueang, was a measure taken by the national government post-20 I to protect the city from future floods (Marks and Thomalla, 20I7). The Thai government provided support to businesses in Bangkok after the 20I I floods, while SMEs in the study explained that they supported each other and the community, for example by providing transportation and meals. 64 per cent of studied SMEs received practical support (e.g. transportation services, free food and medication) from the military and financial support from the government. Every damaged household or business in Don Mueang could get compensation by providing the Bangkok Metropolitan Authority with evidence of the damage. Still, most of the studied SMEs explained that the compensation of 20,000 baht $\left(€_{5} 60\right)$ was not enough to cover the financial and physical damage. This led to protests by SME owners in the Bang Bua Thong part of Bangkok, while a number of communities in Don Mueang, including SME owners, sued the national government and requested further compensation (Marks and Thomalla, 20I7).

Across the three cases, it became clear that although policy frameworks are becoming more inclusive of different social actors, including businesses, implementation of policies is still lacking. Moreover, articulation of specific SMEs needs and challenges is incidental. Possibilities for individual SMEs to obtain support were limited in most cases, and were not focused on long-term business viability. While measurements taken impact SMEs considerably (positively and negatively) SMEs appear to lack power to directly influence the nature of interventions. 


\section{Conclusions}

This article focuses on SMEs and flooding in flood prone areas in Jakarta, Bangkok and Metro Manila, and aims to contribute to the emerging literature on SMEs and flood risks. By considering risk as constructed and taking a political ecology approach, it emphasises SME vulnerability, experiences and perceptions, as well as the socialpolitical dimensions of these. The three cases allow this article to distinguish between what is locally specific and what holds across multiple cases.

Being situated in low-lying areas, close to waterways, it may not come as a surprise that a high percentage of studied SMEs reported experiences with flooding. Indeed, more than 95 per cent of businesses in the selected areas have dealt with flooding at some point in their existence. Impacts of flood experiences were varied but across the three cases it became clear that the (combined) effects that threaten immediate continuation of the business are considered most detrimental.

An important finding from this study is that regardless of source of flooding (e.g. pluvial or tidal), the entrepreneurs distinguish between two types of floods: major floods and 'everyday' floods. Within the last ten years, all three cities have experienced a major flood, which have impacted nearly all SMEs interviewed. Much more prominent however, were so-called 'everyday floods', which occur up to multiple times per week, usually during monsoon or tidal changes. All SMEs acknowledged these floods but whereas SMEs in Bangkok and two areas in Jakarta have seen an increase in their occurrence, local interventions in Manila and in one community in Jakarta have reduced their incidence, at least temporarily. This distinction between major and 'everyday' floods holds theoretical relevance as it relates to how entrepreneurs frame and perceive flood risks, and subsequently take action. While the 'everyday' floods occur frequently and SMEs need to deal with them often, SMEs associate risks with major floods and not so much with the 'everyday' floods that occur in the rainy season or with tidal changes. It is known from other research that the incidence and impact of everyday floods are underestimated and we also know that risk perceptions (co-) shape adaptive action.

This study brings forward three, related, reasons why the impact of everyday floods may be underestimated and how this results in less articulated adaptive actions. Firstly, SMEs seem to have 'normalised' the everyday floods as these have been part of their everyday operation. They have carved out balanced strategies to live with floods and other risks and to adapt to these both cognitively and materially. Such 'normalisation' is also indicated by Arabindoo (2016) in her reflection on the Chennai (India) floods. She indicates that such normalisation is more prevalent among vulnerable populations that experience floods more often. Secondly, SMEs consider the major impact of flood to be business disruption, which is avoided at all cost. Based on incremental building of strategies to avoid disruptions, everyday floods are not threatening business 
continuation and are therefore considered a smaller threat than major floods. Finally, SMEs' strategies enable them successfully and independently to cope with everyday floods, but for the major floods they rely on external actors and interventions. SMEs have not been very successful in tapping into such support. Our findings indicate that for understanding how risks are constructed and perceived by SMEs, in-depth knowledge of their everyday lives and how multiple risks and interventions are interwoven and 'normalised' in daily business practices is crucial. More generally, the importance of normalisation of risk, for vulnerable populations in particular, speaks to Beck's risk society and to urban political ecology debates. Our findings stress that not only risk experiences and adaptive capacity are distributed unequally across populations but also the development of risk perceptions. More specifically our study among SMEs shows how normalisation, everyday coping mechanisms and lack of trust in government action build these. The findings also bring us to argue that in order to develop a comprehensive social-political understanding of flood risks and SMEs we do need to go beyond 'constructivist' notions of risk and include external data, e.g. on flooding, precisely because everyday risks are underestimated (Wedawatta and Ingirige, 2012).

Actions by SMEs are generally restricted to adaptive action, often through elevation of premises. While such measures are not necessarily enough to stop flooding, they guarantee business continuation during floods. With regards to actions, we see a large unevenness between businesses in terms of size. Medium-sized businesses have the means and knowledge for substantial investments to prepare more sustainably for impacts of both everyday and major floods. They are better able to withstand impacts of floods, both using their own means as well as formal institutions (insurance or bank loans). In contrast, smaller enterprises can only avoid business interruption caused by everyday floods and depend on their own funds.

Flood governance was not the core of our study but we did look into the extent to which SMEs were acknowledged in flood policies, and how SMEs related to local governance regarding flooding. SMEs and their specific flooding challenges were absent from most policies and plans, and were not considered a distinctive economic category or subgroup. With the exception of some financial compensation in Bangkok, SMEs generally, and small companies especially, rely on their own resources to prevent or compensate for floods. Hence, while exposure to risks may be similar between businesses of different sizes, our study confirms earlier studies which show that sensitivity and adaptive capacity differ substantially. Meanwhile the study showed how local interventions in Manila and one research community in Jakarta - both directed to economically important areas - have considerable impact on risk perception and experiences of SMEs, at least temporarily. The importance of SMEs for local economies as well as the impact of everyday floods on daily SME operational practices and the need for external support to deal with major floods, calls out to the government at metropolitan and local levels to consider SMEs and their challenges. However, in our 
researched communities we found no evidence of protest or initiatives from SMEs to influence policy development. This may be partly explained by the normalisation of everyday floods. Nevertheless, we would support new research on implicit and explicit forms of resistance and political action by SMEs.

We started off by stating that flood governance and wider environmental or climate action acknowledge the private sector as an important actor but that the sector is treated as a black box and more generally ignores SMEs. Our study confirms the importance of opening up this black box, and shed light on dynamics and diversity within the sector. The specific experiences, needs and opportunities of SMEs and the significant impact of environmental action on them highlight that they are an important group to consider in flood governance. Moreover, their baseline and nuanced knowledge of floods and everyday coping practices make them an important partner in understanding the significance of floods in vulnerable locations and the building of adequate responses.

\section{References}

Abidin, H., Andreas, H., Gumilar, I. and Wibowo, I. (2015) 'On correlation between urban development, land subsidence and flooding phenomena in Jakarta', Proceedings of the International Association of Hydrological Sciences, 370, I5-20.

Agrawala, S., Carraro, M., Kingsmill, N., Lanzi, E. and Prudent-Richard, G. (2013) 'Private sector engagement in adaptation to climate change' (Environment Working Paper No. 39), OECD.

Arabindoo, P. (2016) 'Unprecedented natures?', City, 20(6), 800-82I.

Bankoff, G. (2003) 'Constructing vulnerability: the historical, natural and social generation of flooding in Metro Manila', Disasters, 27(3), 95-109.

Beck, U. (1992) Risk Society: Towards a New Modernity, London and New York, Sage.

Berquist, M., Daniere, A. and Drummond, L. (2015) 'Planning for global environmental change in Bangkok's informal settlements', Journal of Environmental Planning and Management, 58(I0), I7 I I-I730.

Biagini, B. and Miller, A. (2013) 'Engaging the private sector in adaptation to climate change in developing countries: importance, status, and challenges', Climate and Development, 5(3), $242-252$.

Blaikie, P., Cannon, T., Davis, I. and Wisner, B. (2004) At Risk: Natural Hazards, People's Vulnerability and Disasters, London, Routledge.

Bubeck, P., Botzen, W. and Aerts, J. (2012) 'A review of risk perceptions and other factors that influence flood mitigation behavior', Risk Analysis: An International Fournal, 32(9), I481-I495.

Bulkeley, H. and Betsill, M. (2013) 'Revisiting the urban politics of climate change', Environmental Politics, 22(I), I36-I54.

Carland, J., Hoy, F. and Carland, J. (I988) 'Who is an entrepreneur is a question worth asking', American Journal of Small Business, I2(4), 33-39. 
Chinh, D., Bubeck, P., Dung, N. and Kreibich, H. (2016) 'The 20I I flood event in the Mekong Delta: preparedness, response, damage and recovery of private households and small businesses', Disasters, 40(4), 753-778.

Dessai, S., Adger, W., Hulme, M., Turnpenny, J., Kohler, J. and Warren, R. (2004) 'Defining and experiencing dangerous climate change', Climatic Change, 64(I), I I-25.

Devi, S. (2019) 'Cyclone Idai: I month later, devastation persists', The Lancet, 393(Ior8I), I585.

Dodman, D., Johnson, C., Brown, D., Francis, K., Hardoy, J. and Satterthwaite, D. (2013) 'Understanding the nature and scale of urban risk in low- and middle-income countries and its implications for humanitarian preparedness, planning and response' (Working Paper), Human Settlements Discussion Paper Series Climate Change and Cities 4, London, IIED.

Douglas, M. (1992) Risk and Blame: Essays in Cultural Theory, London, Routledge.

Evans, P. (1997) 'The eclipse of the state? Reflections on stateness in an era of globalization', World Politics, 50(I), 62-87.

Falkner, E. and Hiebl, M. (2015) 'Risk management in SMEs: a systematic review of available evidence', The Journal of Risk Finance, I6(2), I22-I44.

Fraser, A., Pelling, M. and Solecki, W. (20r6) 'Understanding risk in the context of urban development: definitions, concepts and pathways', in S. Bartlett and D. Satterthwaite (eds) Cities on a Finite Planet: Towards Transformative Responses to Climate Change, Oxon and New York, Routledge, I7-40.

Füssel, H. (2007) 'Vulnerability: a generally applicable conceptual framework for climate change research', Global Environmental Change, I7(2), I55-167.

Gale, E. and Saunders, M. (2013) 'The 20I I Thailand flood: climate causes and return periods', Weather, 68(9), 233-237.

Garschagen, M., Surtiari, G. and Harb, M. (2018) 'Is Jakarta's new flood risk reduction strategy transformational?', Sustainability, Io(8), 2934.

Gass, P., Hove, H. and Parr, J.-E. (201 I) 'Review of current and planned adaptation action: East and Southeast Asia' (report), International Institute for Sustainable Development, https://www.cakex.org/sites/default/files/documents/East_SouthEastAsia_Adaptation_Action.pdf (accessed io November 2017).

Gera, W. (2018) 'Scalar politics in Philippine urban disaster management: reframing metropolitan governance for local resilience and sustainability, Erdkunde, 72(4), 287-31 I.

Grimm, M., Knorringa, P. and Lay, J. (2012) 'Constrained gazelles: high potentials in West Africa's informal economy', World Development, 40(7), I352-1368.

Ingirige B. and Wedawatta G. (2018) 'An SME-driven approach to adopting measures of flood resilience: a UK-based perspective', in S. Amir (ed.) The Sociotechnical Constitution of Resilience, Singapore, Palgrave Macmillan, 245-264.

IPCC (Intergovernmental Panel on Climate Change) (2014) 'Annex II: glossary', in Climate Change 20I4: Synthesis Report. Contribution of Working Groups I, II and III to the Fifth Assessment Report of the Intergovernmental Panel on Climate Change, Geneva, IPCG, II7-I30.

Jha, A., Bloch, R. and Lamond, J. (2012) Cities and Flooding: A Guide to Integrated Urban Flood Risk Management for the 2Ist Century, Washington, DC, World Bank and GFDRR.

Josephson, A., Schrank, H. and Marshall, M. (2017) 'Assessing preparedness of small businesses for hurricane disasters: analysis of pre-disaster owner, business and location characteristics', International Fournal of Disaster Risk Reduction, 23, 25-35. 
Lebel, L. and Lebel, P. (2018) 'Policy narratives help maintain institutional traps in the governance of floods in Thailand', International Journal of Water Resources Development, 34(4), 6i6-63г.

Marks, D. (2015) 'The urban political ecology of the 20I I floods in Bangkok: the creation of uneven vulnerabilities', Pacific Affairs, 88(3), 623-651.

Marks, D. and Thomalla, F. (2017) 'Responses to the 20I I floods in Central Thailand: perpetuating the vulnerability of small and medium enterprises?', Natural Hazards, 87(2), I I47-1 I65.

McGranahan, G., Balk, D. and Anderson, B. (2007) 'The rising tide: assessing the risks of climate change and human settlements in low elevation coastal zones', Environment and Urbanization, I9(I), I7-37.

Moser, C., Norton, A., Stein, A. and Georgieva, S. (2010) Pro-poor Adaptation to Climate Change in Urban Centers: Case Studies of Vulnerability and Resilience in Kenya and Nicaragua, Washington, DC, World Bank.

Naldi, L., Nordqvist, M., Sjoberg, K. and Wiklund, J. (2007) 'Entrepreneurial orientation, risk taking, and performance in family firms', Family Business Review, 20(I), 33-47.

Neise, T. and Diez, J. (2019) 'Adapt, move or surrender? Manufacturing firms' routines and dynamic capabilities on flood risk reduction in coastal cities of Indonesia', International Fournal of Disaster Risk Reduction, 33, 332-342.

North, P. (2016) 'The business of the Anthropocene? Substantivist and diverse economies perspectives on SME engagement in local low carbon transitions', Progress in Human Geography, 40(4), 437-454.

Padawangi, R. and Douglass, M. (2015) 'Water, water everywhere: toward participatory solutions to chronic urban flooding in Jakarta', Pacific Affairs, 88(3), 517-550.

Parthasarathy, D. (2015) 'Informality, resilience, and the political implications of disaster governance', Pacific Affairs, 88(3), 55 ${ }^{\mathrm{I}-575}$.

Patankar, A. and Patwardhan, A. (20I6) 'Estimating the uninsured losses due to extreme weather events and implications for informal sector vulnerability: a case study of Mumbai, India', Natural Hazards, 80(I), 285-310.

Pathak, S. and Ahmad, M. (2016) 'Flood recovery capacities of the manufacturing SMEs from floods: a case study in Pathumthani province, Thailand', International Fournal of Disaster Risk Reduction, I8, I97-205.

Phien-wej, N., Giao, P. and Nutalya, P. (2006) 'Land subsidence in Bangkok, Thailand', Engineering Geology, 82(4), I87-201.

Plummer, R., Baird, J., Bullock, R., Dzyundzyak, A., Dupont, D., Gerger Swartling, Å., Johannessen, A., Huitema, D., Lyth, A., de Lourdes Melo Zurita, M. and Munaretto, S. (2018) 'Flood governance: a multiple country comparison of stakeholder perceptions and aspirations', Environmental Policy and Governance, 28(2), 67-81.

Porio, E. (2014) 'Climate change vulnerability and adaptation in Metro Manila: challenging governance and human security needs of urban poor communities', Asian Fournal of Social Science, 42(I/2), 75-102.

Posuk, S., Kajita, Y. and Petchsasithon, A. (2018) 'Comparative analysis of city planning and land use change in Bangkok, Thailand, by using remote sensing and GIS', MATEC Web 
Conference, I92, 02064, https://doi.org/I0.IO5I/matecconf/201819202064 (accessed IO November 20I7).

Pribadi, D., Vollmer, D. and Pauleit, S. (2018) 'Impact of peri-urban agriculture on runoff and soil erosion in the rapidly developing metropolitan area of Jakarta, Indonesia', Regional Environmental Change, I8(7), 2129-2143.

Redshaw, P., Boon, D., Campbell, G., Willis, M., Mattai, J., Free, M., Jordan, C., Kemp, S. J., Morley, A. and Thomas, M. (2019) 'The 2017 Regent landslide, Freetown Peninsula, Sierra Leone', Quarterly Journal of Engineering Geology and Hydrogeology, 52(4), 435-444.

Saito, N. (20I4) 'Challenges for adapting Bangkok's flood management systems to climate change', Urban Climate, 9, 89-100.

Schaer, C. and Kuruppu, N. (eds) (2018) 'Private-sector action in adaptation: perspectives on the role of micro, small and medium size enterprises' (report), Copenhagen, UNEP DTU Partnership.

Sealey-Huggins, L. (2017) "I. $5^{\circ} \mathrm{C}$ to stay alive": climate change, imperialism and justice for the Caribbean', Third World Quarterly, 38(I I), 2444-2463.

Sebastian, A., Lendering, K., Kothuis, B., Brand, A., Jonkman, S., van Gelder, P., Godfroij, M., Kolen, B., Comes, M., Lhermitte, S. and Meesters, K. (2017) 'Hurricane Harvey report: a fact-finding effort in the direct aftermath of Hurricane Harvey in the Greater Houston Region' (report), Delft, Delft University Publishers.

Swyngedouw, E. (2004) Social Power and the Urbanization of Water: Flows of Power, Oxford, Oxford University Press.

Takagi, H., Fujii, D., Esteban, M. and Yi, X. (2017) 'Effectiveness and limitation of coastal dykes in Jakarta: the need for prioritizing actions against land subsidence', Sustainability, 9(4), 6rg.

van Voorst, R. (2016) 'Formal and informal flood governance in Jakarta, Indonesia', Habitat International, 52, 5-I0.

Verrest, H. (2013) 'Rethinking microentrepreneurship and business development programs: vulnerability and ambition in low-income urban Caribbean households', World Development, $47,5^{8-70 .}$

Wallemacq, P. and House, R. (2018) 'Economic losses, poverty and disasters I998-20I7' (report), United Nations Office for Disaster Risk Reduction (UNISDR) and Centre for Research on the Epidemiology of Disasters (CRED), https://www.unisdr.org/files/6r I I9_credeconomiclosses.pdf (accessed Io January 20I9).

Wedawatta, G. and Ingirige, B. (2012) 'Resilience and adaptation of small and medium-sized enterprises to flood risk', Disaster Prevention and Management: An International Journal, 2I(4), $474-488$.

Wedawatta, G., Ingirige, B. and Proverbs, D. (2014) 'Small businesses and flood impacts: the case of the 2009 flood event in Cockermouth', Fournal of Flood Risk Management, 7(I), 42-53.

Wong, P. Losada, I., Gattuso, J.-P., Hinkel, J., Khattabi, A., McInnes, K. L., Saito, Y. and Sallenger, A. (2014) 'Coastal systems and low-lying areas', in C. Field, V. Barros, K. Mach and M. Mastrandrea (eds) Climate Change 20I4: Impacts, Adaptation, and Vulnerability. Part A: Global and Sectoral Aspects, Contribution of Working Group II to the Fifth Assessment Report, IPCC, Cambridge, Cambridge University Press, 36I-409. 